\title{
Hormonal and Metabolic Effects of Chlorpropamide, Glibenclamide and Placebo in a Cross-over Study in Diabetics not Controlled by Diet Alone
}

\author{
P. H. Sönksen, C. Lowy, J. R. Perkins, and T. E. T. West \\ Departments of Medicine and Chemical Pathology, St. Thomas's Hospital Medical School, London, England
}

Summary. Twenty diabetic patients, whose hyperglycaemia had been shown to fail to respond to at least one month's dietary treatment, completed a crossover study in order to: 1) compare the effectiveness of two sulphonylureas, chlorpropamide and glibenclamide, and 2) study the effects of sulphonylureas on insulin secretion and on biochemical indices of glucose intolerance. Fasting blood glucose fell on active treatment from $10.7 \pm 0.6$ (mean \pm SEM) to $6.6 \pm$ $0.7 \mathrm{mmol} / 1$ and rose again to $10.6 \pm 0.7$ after 4 months placebo. A second period of 4 months sulphonylurea therapy resulted in a comparable fall in blood glucose (to $6.9 \pm 0.7 \mathrm{mmol} / \mathrm{l}$ ) and a similar relapse was seen after the second placebo period (to $10.5 \pm 0.9 \mathrm{mmol} / \mathrm{l})$. Glucose tolerance and associated insulin secretion improved markedly on active treatment, with ketone bodies, non-esterified fatty acids, and glycerol falling to within the reference range. Sulphonylurea therapy was associated with a small but significant increase in the fasting insulin level. These effects were nearly all reversed 4 months after withdrawal of the sulphonylureas. No marked changes were found in growth hormone, lactate, pyruvate, lactate/pyruvate ratio or fasting cholesterol, triglycerides and lipoproteins. On a weight basis, glibenclamide was 26 times more potent than chlorpropamide and, in the doses used in this study, their biochemical effects were indistinguishable. The effects of these two sulphonylureas seem most likely to be mediated by a direct stimulation of insulin secretion by the B-cell.

Key words: Non insulin dependent diabetes, sulphonylurea therapy, chlorpropamide, glibenclamide.

The hypoglycaemic action of sulphonylureas was described over 30 years ago [1] and this class of drugs has been in widespread use for the treatment of non insulin dependent diabetes since the 1950's. Glibenclamide was introduced in 1969 , as the first of the more potent sulphonylureas [2]. Despite the long history of sulphonylurea treatment, there is a surprising lack of agreement as to their mode of action, particularly with respect to their effect on insulin secretion [3]. We have therefore set out to examine the role of insulin in long-term sulphonylurea therapy, by measuring glucose tolerance and circulating plasma concentrations of hormones and a range of intermediary metabolites, known to be affected by insulin. Secondly, we wished to compare two sulphonylureas in widespread use, chlorpropamide, one of the original agents, with glibenclamide. One of the major problems in interpreting results of earlier studies has been the simultaneous introduction of dietary advice and the drug. In this study, we separated these effects by selecting only patients who had not had a remission in their diabetes, and who still showed marked glucose intolerance, following a period of closelysupervised dietary therapy.

\section{Patients and Methods}

\section{Patients}

Freshly-presenting, symptomatic, diabetic outpatients whose glucose tolerance had not responded satisfactorily to diet alone, were selected for inclusion in this study. All patients had been selected prior to dietary treatment on the following criteria:

1) aged 18 to 65 years, 2) not pregnant, 3) 85 to $130 \%$ desirable body weight (DBW) for height (Metropolitan Life Assurance Tables), 4) absence of any other major illness and 5) not being treated with drugs likely to affect carbohydrate or lipid metabolism (corticosteroids, monoamine oxidase inhibitors, sulphonamides and oral anticoagulants). A $5 \mathrm{~h}, 100 \mathrm{~g}$ glucose tolerance test (OGTT) was performed at the time of presentation and patients gave their informed consent after the purpose and conduct of the study had been explained to them. Forty parients were seen by a dietician, who assessed their current carbohydrate and energy intake and advised on carbohydrate restriction. Since fats and proteins were not increased dietary regimes consisted of energy and 


\begin{tabular}{|c|c|c|c|c|c|c|}
\hline \multirow{3}{*}{ TREATMENT } & \multirow{2}{*}{$\begin{array}{l}\text { Period } \\
\text { Diet }\end{array}$} & \multicolumn{2}{|r|}{$I$} & $I I$ & $I I I$ & $I V$ \\
\hline & & \multicolumn{5}{|c|}{ Corbohydrate and energy restriction } \\
\hline & Drug & & Drug & Plocedo & Drug & $\begin{array}{c}\text { Plocebo } \\
2\end{array}$ \\
\hline & $\begin{array}{c}\text { Duration, } \\
\text { monthss }\end{array}$ & $\not 1$ & 4 & 4 & 4 & 4 \\
\hline
\end{tabular}

$\begin{array}{cccccc}\text { O.G.T.T. Number } & 1 & 2 & 3 & 4 & 5 \\ \text { Symbol } & \mathbf{1} & 0 & \Delta & \bullet & 4\end{array}$

Fig. 1. Design of the study: Patients completed at least 1 month dietary therapy without improvement in glucose tolerance betore entering the study. Patients were randomly assigned to either chlorpropamide, or glibenclamide for the first of 4 four month treatment periods (Drug 1). This was followed by a placebo period APlacebo 1) and then in Drug 2 patients were treated with the sulphonylurea that they had not received in Drug 1 and the study was completed with a second placebo period (Placebo 2). Oral glucose tolerance tests were carried out at entry $(1, \mathbf{n})$, at the end of Drug $1(2,0)$, Placebo $1(3, \Delta)$, Drug $2(4, \bullet)$ and placebo 2 $(5, \Delta)$

carbohydrate restriction. After 4 weeks of diet treatment, each patient received a second $5 \mathrm{~h}, 100 \mathrm{~g}$ OGTT, provided that their DBW was $85-115 \%$. Patients whose DBW was above this level continued on diet alone until this weight goal had been reached, before the second OGTT was performed. The sum of the blood glucose concentrations fasting and at 1,2 and $3 \mathrm{~h}$ during the second OGTT (SUMBG) was calculated. Only patients whose SUMBG was $>33.3 \mathrm{mmol} / 1(600 \mathrm{mg} / 100 \mathrm{ml})$ qualified for entry into the study.

\section{Design of the Study}

The study was an open, cross-over trial of chlorpropamide and glibenclamide therapies. Patients were randomly assigned to two treatment groups ( $A$ and $B$ ), with stratification above and below SUMBG of $61.1 \mathrm{mmol} / 1(1100 \mathrm{mg} / 100 \mathrm{ml})$ ensuring equal numbers of the most severe diabetics in both groups. Group A received chlorpropamide as the first active drug (Fig. 1), while group B received glibenclamide. Each period of sulphonylurea treatment lasted 4 months and was followed by a 4 month period on placebo (ascorbic acid). Maintenance of dietary restrictions was advised throughout the study. OGTTs were performed at the end of each 4 month period (Fig. 1). During each treatment period patients were reviewed in the Diabetic Clinic at 2 weeks and at 1,2 and 3 months. At each visit, the results of home urine tests (Clinitest, Ames), clinic post-prandial blood glucose concentrations (Dextrostix and Reflectance Meter, Ames) were used to assess diabetic control. Specific enquiry was made about any drug side-effects and other symptoms. During periods of active (sulphonylurea) treatment, the doses of chlorpropamide and glibenclamide were adjusted to achieve adequate diabetic control (postprandial blood glucose concentration between 3.9 and $8.3 \mathrm{mmol} / \mathrm{l}$ and at least $80 \%$ of fasting urine tests showing no glycosuria). The maximum daily doses were $750 \mathrm{mg}$ of chlorpropamide and $30 \mathrm{mg}$ of glibenclamide. The dose of placebo was altered on the same criteria, up to a maximum daily dose of $300 \mathrm{mg}$, as six $50 \mathrm{mg}$ tablets.

Loss of diabetic control was defined as two consecutive clinic post-prandial blood glucose concentrations over $13.1 \mathrm{mmol} / 1$ $(235 \mathrm{mg} / 100 \mathrm{ml})$, or more than half of the home urine tests show- ing $\geqslant 2 \%$ giycosuria. If this occurred during an active treatment period and the patient had been taking the maximum dose of the drug, the patient left the trial and was started on insulin. When such loss of control occurred during a placebo period, a glucose tolerance test was carried out and the patient started on the next active drug.

\section{OGTT's}

Dietary restriction was maintained until the day of each OGTT (no increase in carbohydrate intake was advised) and the last dose of drug taken on the day preceding the OGTT. All the tests were done in the morning after an overnight fast $(>11 \mathrm{~h})$, the patients remaining recumbent throughout the test. A plastic cannula for blood sampling was inserted into a forearm vein under local anaesthesia and was kept patent with $0.15 \mathrm{~mol} / 1$ sodium chloride. After two fasting blood samples (separated by $10 \mathrm{~min}$ ) had been taken, the patients drank $100 \mathrm{~g}$ glucose in $250 \mathrm{ml}$ water (within $10 \mathrm{~min}$ ) flavoured with unsweetened lemon juice. Blood was sampled at $15,30,45,60,90,120,180,240$ and 300 min after glucose ingestion. Measurements were made of: blood glucose; serum insulin (IRI) and growth hormone (hGH); blood lactate, pyruvate, 3hydroxybutyrate, acetoacetate and glycerol; plasma non-esterfied fatty acids (NEFA). Fasting plasma cholesterol, triglycerides and lipoproteins were measured in blood taken at 0 min.

\section{Analytical Methods}

Blood glucose was measured by an automated, glucose oxidase method $[4,5]$. Serum IRI and hGH concentrations were measured by a combined, double-antibody radioimmunoassay [6]. Enzymatic methods were used to measure lactate and pyruvate [7],3hydroxybutyrate, acetoacetate [8] and glycerol [9] (blood for these determinations was taken into an equal volume of cold, $1 \mathrm{~mol} / 1$ perchloric acid). Samples were either analysed on the day of the test or were immediately deep frozen at $-20^{\circ} \mathrm{C}$ and analysed within 1 week. In control studies no deterioration of sample was detectable within this time. NEFA [10] and triglycerides [11] were estimated fluorimetrically in extracts of plasma. Cholesterol was measured colorimetrically [12]. Lipoprotein electrophoresis [13] was performed on the day of the OGTT, using agarose gel; after staining with sudan black, bands were quantitated with a scanning densitometer and expressed as percentages of total lipid staining.

\section{Statistical Analysis}

Values measured throughout each OGTT were first assessed by 3 way analysis of variance, after transforming the data logarithmically, with patients, OGTT number and times of measurement in OGTT's as factors [14]. The main interest was in the difference between OGTT's. There were the expected differences between patients and between times of measurement in OGTT's. Where response curves were not significantly non-parallel (there was no significant 2-way interaction between OGTT number and times in OGTT), the residual estimate of variance was used for comparisons between mean values in each OGTT. Where shapes of response curves changed after each treatment period, the simple main effect of OGTT number was assessed by 2-way analysis of variance at each time of measurement in OGTT's. This method was also used for single measurements at each OGTT (weight, cholesterol, triglycerides and lipoproteins).

No true control group of age and sex matched nondiabetic subjects was studied. The reference ranges used are $95 \%$ confidence limits derived from the results of $100 \mathrm{~g}$ OGTT's performed on 24 healthy medical students and members of laboratory staff (age $28 \pm 9$ years (mean $\pm \mathrm{SD}$ ), range $20-59$ years). These refer- 
Table 1. Clinical details of patient groups at diagnosis

\begin{tabular}{|c|c|c|}
\hline & Group: & B \\
\hline $\begin{array}{l}\text { Number in group } \\
\text { Male } \\
\text { Female }\end{array}$ & $\begin{array}{l}8 \\
6 \\
2\end{array}$ & $\begin{array}{r}12 \\
7 \\
5\end{array}$ \\
\hline $\mathrm{Age}^{\mathrm{b}}, \mathrm{yr}$ & $54(39-65)$ & $52(26-64)$ \\
\hline Weight ${ }^{b}, \mathrm{~kg}$ & $63(59-72)$ & $66(52-84)$ \\
\hline Percentage of $\mathrm{DBW}^{1}, \%$ & $103(89-130)$ & $108(91-127)$ \\
\hline $\begin{array}{l}\text { Prevalence of: } \\
\text { Retinopathy } \\
\text { Neuropathy } \\
\text { Ischaemic heart disease } \\
\text { Peripheral vascular disease } \\
\text { Family history of diabetes } \\
\text { Previous diabetes } \\
\text { Miscellanea }\end{array}$ & $\begin{array}{c}4 \\
1 \\
1 \\
0 \\
2 \\
1 \\
1 \text { Klinefelter's syndrome } \\
1 \text { Autoimmune thyroiditis } \\
1 \text { Parkinson's disease }\end{array}$ & $\begin{array}{c}3 \\
2 \\
2 \\
1 \\
6 \\
3^{\mathrm{a}} \\
1 \text { chronic lymphatic leukaemia }\end{array}$ \\
\hline
\end{tabular}

a One had previous glycosuria of pregnancy

b Mean with range in parenthesis

Differences between the two groups were not statistically significant, as assessed by 1) chi-squared test, or 2) analysis of variance

ence ranges were calculated after logarithmic transformation of the original data, since significant skewness was initially present with all variables, and this was virtually eliminated by the transformation.

\section{Results}

\section{Patients}

Of 31 patients eligible for entry into the trial, one refused prior to entry and one refused to continue the trial during the first placebo treatment period. Two patients were excluded because of hypoglycaemia during the first period of sulphonylurea therapy and two patients were excluded because of loss of diabetic control during the second active treatment phase (in both cases after shortened periods of placebo treatment). Five patients were excluded because of irregular attendance for clinic review.

Twenty patients thus completed all stages of the trial. Their mean age at entry was 53 years (range 26-65). Eight patients had received chlorpropamide followed by glibenclamide (group A) and 12 glibenclamide followed by chlorpropamide (group B). The clinical findings in these two groups are shown in Table 1 . Three patients had previously been known to have diabetes and one was known to have had gestational diabetes, but all 4 had stopped treatment, including diet, and had relapsed at the time of presentation (none had received insulin treatment). Three patients admitted taking analgesic preparations (2 paracetamol, 1 soluble aspirin), one diazepam (Valium), one benzhexol (Artane, for Par- kinson's disease) and one thyroxine replacement therapy for hypothyroidism due to autoimmune thyroiditis. The mean length of each study period in groups $A$ and $B$ are shown in Table 2 . Active treatment periods (I and III) generally corresponded well to the design but, because of loss of diabetic control, placebo periods (II and IV) were shortened in 6 patients (to between 2 and 8 weeks). Both placebo periods were shortened in two patients and in the other 4 patients only one placebo period was shortened ( 2 in period II and 2 in period IV). The six patients in whom control was lost in placebo periods were all on maximal doses of sulphonylureas at the end of the previous active treatment phase.

\section{Diet and Weight Changes}

Initial dietary assessments and prescribed diets during the study are shown in Table 2. Mean weight and $\%$ DBW (Table 2) increased after active drug treatment (OGTT's 2 and 4) and fell after placebo treatment (OGTT's 3 and 5).

\section{Glucose, Insulin and Growth Hormone (Fig. 2)}

Blood glucose concentrations (both fasting and after oral glucose) fell significantly $(P<0.001)$ after sulphonylurea treatment and rose after placebo. The blood glucose curves improved significantly after sulphonylurea administration ( $\mathrm{P}<0.001$ ), with significantly earlier peaks in mean blood glucose $(P<0.01)$ and significantly smaller rises from fasting to peak 
Table 2. Diet composition, weight change and duration of study periods for groups A and B

\begin{tabular}{|c|c|c|c|c|}
\hline \multirow[t]{2}{*}{ Group } & \multicolumn{2}{|l|}{$A(n=8)$} & \multicolumn{2}{|l|}{$B(n=12)$} \\
\hline & $\mathrm{CHO}, \mathrm{g} / \mathrm{d}$ & Energy, MJ/d & $\mathrm{CHO}, \mathrm{g} / \mathrm{d}$ & Energy, MJ/d \\
\hline \multicolumn{5}{|l|}{ Dietary intake ${ }^{a}$ : } \\
\hline Before study & $233(160-310)$ & $9.6(7.6-11.3)$ & $237(85-355)$ & $10.0(4.4-13.5)$ \\
\hline During study & $130(105-155)$ & $6.4(4.8-7.6)$ & $143(95-210)$ & $6.8(4.7-9.8)$ \\
\hline \multicolumn{5}{|c|}{ Mean final drug dose ${ }^{\mathrm{a}} ; \mathrm{mg} / \mathrm{d}$ : } \\
\hline Drug: 1 & \multicolumn{2}{|c|}{$\begin{array}{l}\text { C } 264(50-500) \\
\text { G } 12.5(2.5-30)\end{array}$} & \multicolumn{2}{|c|}{$\begin{array}{l}\text { G } 15.2(5-30) \\
\text { C } 421 \quad(250-750)\end{array}$} \\
\hline Weight ${ }^{\mathrm{t}}$ : & Absolute, $\mathrm{kg}$ & DBW, \% & Absolute, $\mathrm{kg}$ & DBW, \% \\
\hline OGTT: 1 & $61.8 \pm 2.0$ & $100.1 \pm 3.7$ & $64.0 \pm 2.7$ & $103.7 \pm 2.7$ \\
\hline 2 & $61.4 \pm 2.0$ & $99.5 \pm 3.3$ & $65.9 \pm 3.3$ & $106.6 \pm 3.5$ \\
\hline 3 & $60.1 \pm 1.9$ & $97.5 \pm 3.8$ & $64.2 \pm 2.9$ & $104.0 \pm 3.0$ \\
\hline 4 & $62.5 \pm 2.1$ & $101.5 \pm 3.7$ & $65.3 \pm 3.1$ & $105.6 \pm 3.0$ \\
\hline 5 & $60.9 \pm 2.2$ & $98.9 \pm 4.2$ & $63.5 \pm 2.9$ & $102.8 \pm 3.0$ \\
\hline \multicolumn{5}{|c|}{ Duration of stage ${ }^{a}$, Wk: } \\
\hline Period: I & \multicolumn{2}{|c|}{$18(16-19)$} & \multicolumn{2}{|c|}{$17(13-21)$} \\
\hline II & \multicolumn{2}{|c|}{$15(6-19)$} & \multicolumn{2}{|c|}{$15(6-19)$} \\
\hline III & \multicolumn{2}{|c|}{$18(14-27)$} & \multicolumn{2}{|c|}{$17(15-22)$} \\
\hline IV & \multicolumn{2}{|c|}{$16(8-20)$} & \multicolumn{2}{|c|}{$14(2-18)$} \\
\hline
\end{tabular}

${ }^{2}$ Mean with range in parenthesis

Mean \pm SEM
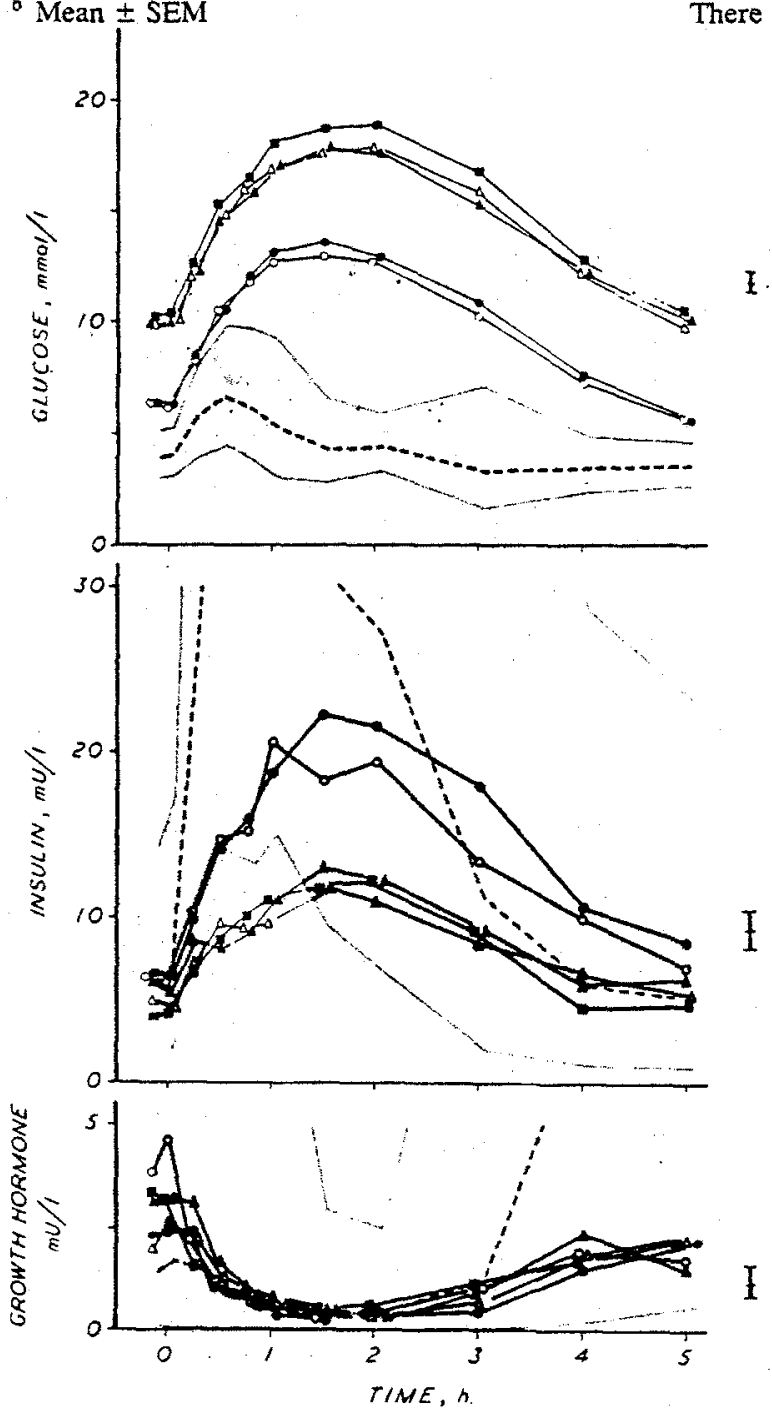

\section{I}

CHO indicates carbohydrate, $C$ indicates chlorpropamide and $G$, Glibenclamide There was no significant difference between values for groups $A$ and $B$

Fig. 2. Concentrations of glucose, insulin and growth hormone at each OGTT during the study: Values are geometic means, with the pooled SEM (from the analysis of variance) shown above and below the grand mean at the right. Shading represents the reference ranges, with the reference mean as an interrupted line. Symbols as Figure 1 tolerance was not restored.

Mean fasting insulin concentrations were similar to the reference mean, but values after sulphonylureas were significantly higher $(P<0.05)$ than those after diet alone or with a placebo. The insulin response to oral glucose, between 0.5 and $4 \mathrm{~h}$, was also significantly higher after sulphonylureas and the shape of the insulin response curve had changed significantly $(p<0.02)$ with a more rapid rise in plasma insulin and a higher peak insulin concentration. After each period of placebo treatment, both fasting and postglucose insulin concentrations were lower. The initial insulin response to glucose was subnormal on diet alone and placebo, but rose into the lower part of the reference range after active treatment. The average peak insulin response to glucose remained delayed even after sulphonylureas.

Sulphonylurea treatment had no effect on the shape of the $\mathrm{GH}$ curve or on $\mathrm{GH}$ concentrations, all of which were within the reference range.

\section{Lactate and Pyruvate}

Mean lactate and pyruvate concentrations and lactate/pyruvate ratios were within the reference 

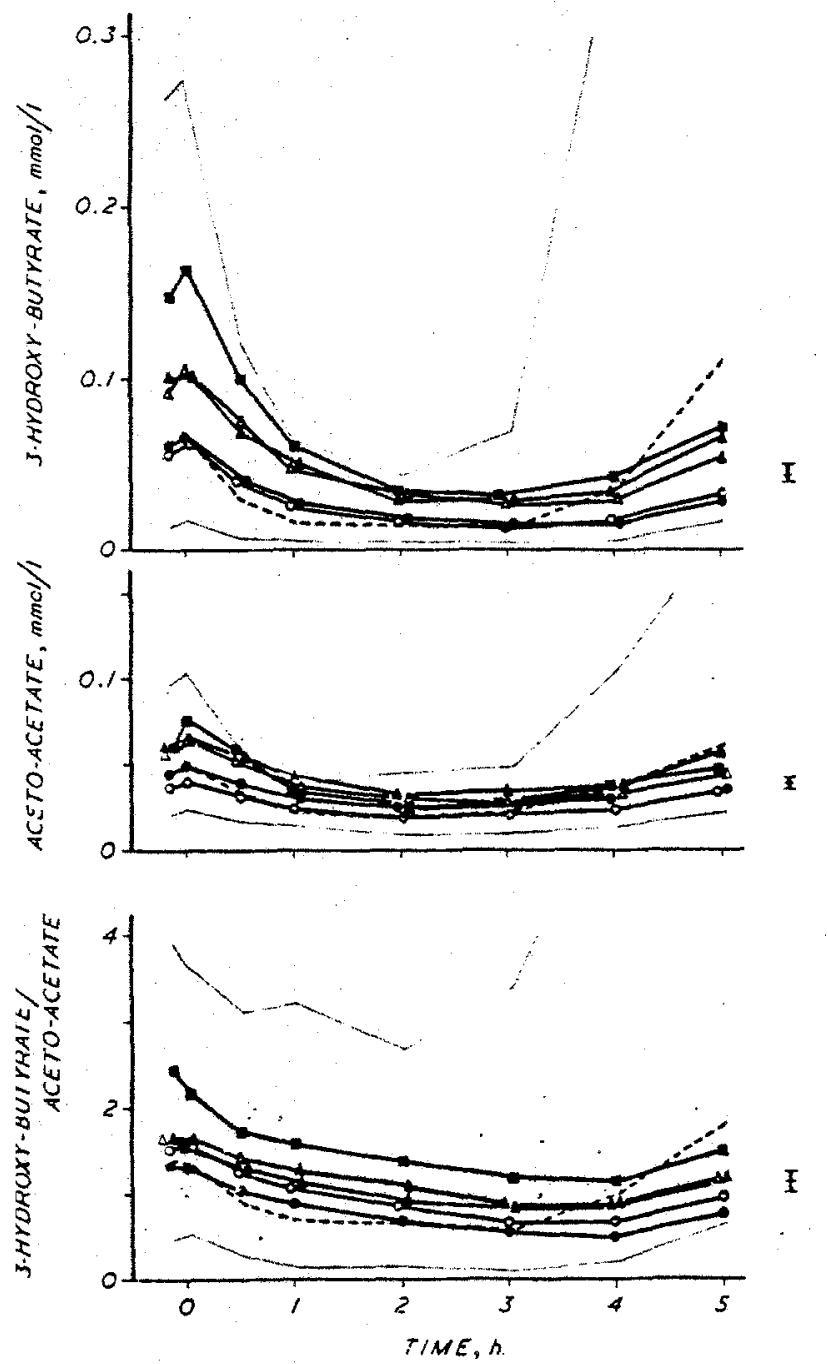

Fig. 3. Concentrations of 3-hydroxybutyrate and acetoacetate, and 3-hydroxybutyrate/acetoacetate ratio at each OGTT: Symbols are as given in Figure 1, for further explanation, see the legend to Figure 2 and the text

ranges, although peak lactate concentrations occurred at $2 \mathrm{~h}$ (rather than at $1 \mathrm{~h}$ in the reference group). There were no clear-cut trends after sulphonylurea therapy.

Ketone Bodies, Glycerol and NEFA (Figs. 3 and 4)

Mean concentrations of these two ketone bodies were elevated on diet treatment alone and diet and placebo but, unlike blood glucose, fell to within the normal range on sulphonylurea treatment. These improvements were statistically significant $(P<0.001$ for 3-hydroxybutyrate, and $P<0.02$ for acetoacetate). Relapse after withdrawal of the second active treatment was less marked than after the first. Ratios of 3-hydroxybutyrate/acetoacetate were lowest after

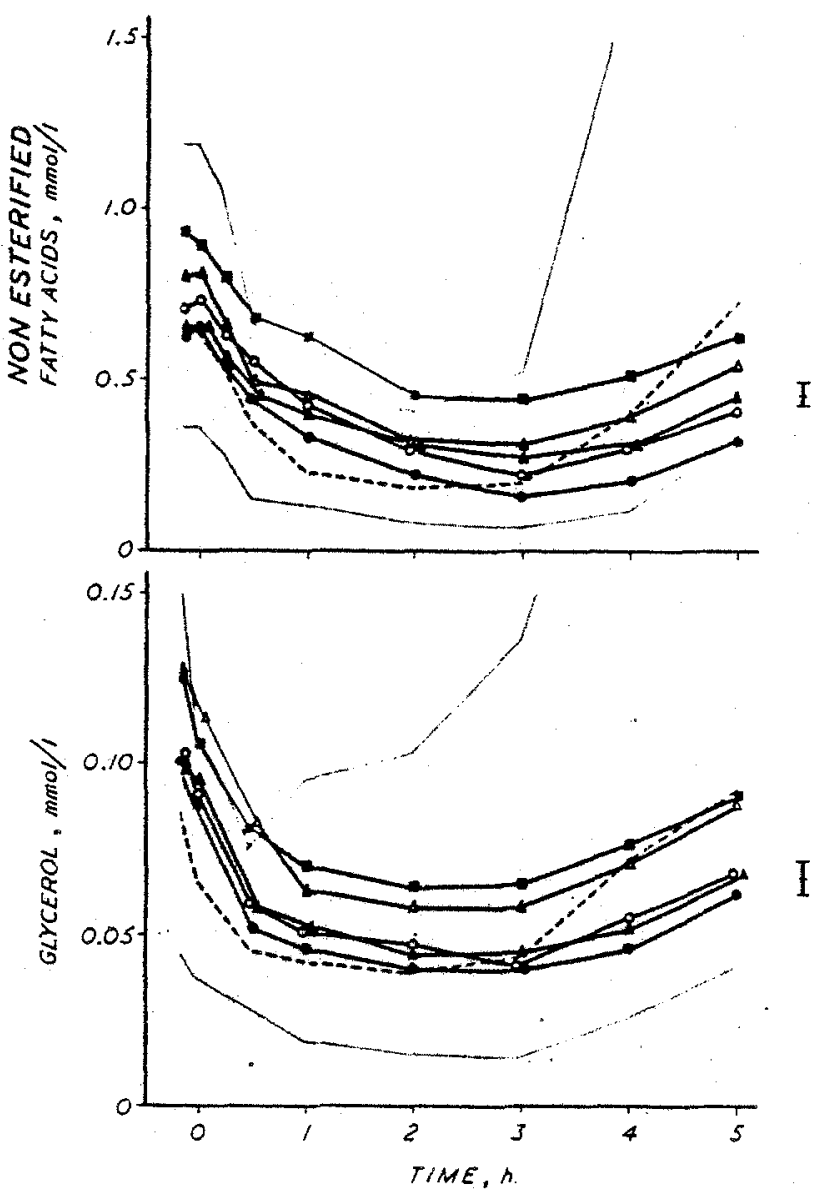

Fig. 4. Concentrations of non-esterified fatty acids and glycerol at each OGTT: Symbols are as given in Figure 1, for further explanation, see the legend to Figure 2 and the text

the second period of active treatment. The patterns of change in NEFA and glycerol concentrations after diet and after sulphonylurea were the same as for the ketone bodies. The relapse in NEFA after the second placebo treatment was less than after the first and there was no relapse in blood glycerol concentrations.

\section{Fasting Lipids}

Mean lipid concentrations (cholesterol, triglycerides and lipoproteins) were within normal limits and showed no significant changes on treatment, except for triglycerides, which showed a minor increase during the study $(\mathrm{P}<0.02)$. Some patients showed a double pre- $\beta$ lipoprotein band ( 5 in first, third and 
Table 3. Fasting hormone and metabolite levels during trial

\begin{tabular}{|c|c|c|c|c|c|c|c|}
\hline $\begin{array}{l}\text { OGTT number } \\
\text { Symbol } \\
\text { Number of patients }\end{array}$ & $\begin{array}{l}(1) \\
\square \\
18\end{array}$ & $\begin{array}{l}(2) \\
\vdots \\
20\end{array}$ & $\begin{array}{l}(3) \\
\bigcirc \\
20\end{array}$ & $\begin{array}{l}(4) \\
\triangle \\
20\end{array}$ & $\begin{array}{l}(5) \\
9 \\
20\end{array}$ & $\begin{array}{l}(6) \\
\mathbf{A} \\
20\end{array}$ & $\begin{array}{l}\text { Reference } \\
\text { values } \\
24\end{array}$ \\
\hline Glucose (mmol/l) & $12.7 \pm 0.8$ & $10.7 \pm 0.6$ & $6.6 \pm 0.7$ & $10.6 \pm 0.7$ & $6.9 \pm 0.7$ & $10.5 \pm 0.9$ & $4.0 \pm 0.1$ \\
\hline Insulin $(\mathrm{mU} / \mathrm{l})$ & $4.7 \pm 0.9$ & $5.3 \pm 0.8$ & $7.4 \pm 1.0$ & $5.0 \pm 0.6$ & $7.2 \pm 0.7$ & $6.5 \pm 0.6$ & $6.7 \pm 0.8$ \\
\hline Growth hormone (mU/l) & $7.0 \pm 1.7$ & $8.0 \pm 2.5$ & $9.8 \pm 2.8$ & $7.1 \pm 2.5$ & $5.4 \pm 1.5$ & $6.7 \pm 2.0$ & $7.2 \pm 2.6$ \\
\hline Lactate $(\mathrm{mmol} / \mathrm{l})$ & $1.1 \pm 0.1$ & $1.05 \pm 0.05$ & $0.98 \pm 0.06$ & $1.33 \pm 0.1$ & $1.2 \pm 0.09$ & $1.2 \pm 0.1$ & $0.72 \pm 0.04$ \\
\hline Pyruvate (mmol/1) & $0.08 \pm 0.006$ & $0.07 \pm 0.005$ & $0.07 \pm 0.004$ & $0.09 \pm 0.006$ & $0.08 \pm 0.005$ & $0.09 \pm 0.008$ & $0.06 \pm 0.004$ \\
\hline $\mathrm{L} / \mathrm{P}$ ratio & $14.7 \pm 0.7$ & $15.5 \pm 1.0$ & $15.8 \pm 1.0$ & $15.9 \pm 1.1$ & $15.0 \pm 1.5$ & $13.2 \pm 0.7$ & $11.6 \pm 0.4$ \\
\hline 3-hydroxybutyrate $(\mathrm{mmol} / \mathrm{l})$ & $0.4 \pm 0.13$ & $0.21 \pm 0.04$ & $0.07 \pm 0.01$ & $0.22 \pm 0.09$ & $0.09 \pm 0.02$ & $0.16 \pm 0.04$ & $0.09 \pm 0.02$ \\
\hline Acetoacetate $(\mathrm{mmol} / \mathrm{l})$ & $0.13 \pm 0.02$ & $0.09 \pm 0.01$ & $0.05 \pm 0.006$ & $0.09 \pm 0.03$ & $0.06 \pm 0.008$ & $0.08 \pm 0.02$ & $0.05 \pm 0.004$ \\
\hline \multicolumn{7}{|l|}{ 3-hydroxybutyrate acetoacetate } & 1.52 \\
\hline Glycerol (mmol/l) & $0.12 \pm 0.008$ & $0.11 \pm 0.01$ & $0.1 \pm 0.01$ & $0.12 \pm 0.01$ & $0.10 \pm 0.01$ & $0.10 \pm 0.01$ & $0.07 \pm 0.004$ \\
\hline NEFA $(\mathrm{mmol} / \mathrm{l})$ & $1.03 \pm 0.06$ & $0.92 \pm 0.05$ & $0.73 \pm 0.04$ & $0.89 \pm 0.1$ & $0.69 \pm 0.05$ & $0.71 \pm 0.06$ & $0.66 \pm 0.04$ \\
\hline Cholesterol (mmol/1) & $5.3 \pm 0.3$ & $5.0 \pm 0.2$ & $5.2 \pm 0.2$ & $5.3 \pm 0.2$ & $5.2 \pm 0.2$ & $5.1 \pm 0.2$ & $4.8 \pm 0.2$ \\
\hline $\begin{array}{l}\text { Triglycerides (mmol/1) } \\
\text { Lipoproteins }\end{array}$ & $0.8 \pm 0.1$ & $0.7 \pm 0.05$ & $0.8 \pm 0.1$ & $0.9 \pm 0.1$ & $0.9 \pm 0.1$ & $0.9 \pm 0.1$ & $6.8 \pm 0.1$ \\
\hline (percentage & $33.2 \pm 1.3$ & $37.6 \pm 1.3$ & $38.2 \pm 1.8$ & $37.5 \pm 2.1$ & $35.4 \pm 2.0$ & $36.1 \pm 1.8$ & $37.9 \pm 1.9$ \\
\hline of total & $14.4 \pm 1.2$ & $12.9 \pm 1.2$ & $14.2 \pm 1.4$ & $14.4 \pm 1.6$ & $15.1 \pm 1.7$ & $14.2 \pm 1.3$ & $14.5 \pm 1.1$ \\
\hline staining) & $52.1 \pm 1.3$ & $49.3 \pm 1.1$ & $47.4 \pm 1.6$ & $48.0 \pm 1.2$ & $49.5 \pm 1.5$ & $49.8 \pm 1.8$ & $47.5 \pm 1.5$ \\
\hline Chylomicrons & $0.5 \pm 0.2$ & $0.2 \pm 0.1$ & $0.2 \pm 0.2$ & $0.3 \pm 0.1$ & $0.2 \pm 0.2$ & $0.1 \pm 0.1$ & 0 \\
\hline
\end{tabular}

a See text with Figure 1 for explanation

Results are means \pm SEM

fifth OGTT and 3 in second and fourth OGTT) but it was not consistently observed in the same patients $(6$ of the 24 reference subjects also showed a double pre- $\beta$ band). The prevalence in the diabetics was significantly greater $\left(\chi^{2}=5.7, \mathrm{P}<0.05\right)$ than in the reference subjects, if all the data were analysed, but not if only the diabetics' first OGTT was considered.

\section{Comparisons of Chlorpropamide and Glibenclamide}

There were no significant differences in the final daily doses of each sulphonylurea in groups $\mathrm{A}$ and $\mathrm{B}$ (chlorpropamide: group A, $264(50-500) \mathrm{mg} / \mathrm{d}$ (mean and range), group B $421(250-750) \mathrm{mg} / \mathrm{d}$; glibenclamide: group A, $12.5(2.5-30) \mathrm{mg} / \mathrm{d}$, group B $15.2(5-30) \mathrm{mg} / \mathrm{d})$. When the biochemical results from groups A and B were compared at each stage in the study no significant differences between the effects of the drugs in the two groups were found except for minor ones involving lactate and pyruvate. Patterns of improvement and relapse were the same in each group. This included the greater insulin response to oral glucose after the second period of sulphonylurea treatment and the less marked relapse in insulin, glycerol and NEFA after the second placebo period.

In order to see if there were any demonstrable differences between the effects of the first and second generation sulphonylureas, the effects of chlorpropamide and glibenclamide were compared, irre- spective of the order in which they had been given. All data from OGTT's after chlorpropamide were pooled and compared with all pooled data from OGTT's after glibenclamide. A similar comparison was made of data from OGTT's after the placebo treatment following the respective sulphonylureas. These comparisons showed no significant differences in the effects of the two drugs or any delayed effects still demonstrable after the subsequent placebo periods (Fig. 5).

\section{Discussion}

Since the patterns of metabolic responses were the same for chlorpropamide and glibenclamide, we were able to combine the results from treatment groups $A$ and $B$ in order to examine the sequential effects of repeated sulphonylurea treatment and withdrawal. The principal effects of sulphonylurea therapy in these diabetic patients were: 1) lowered fasting blood glucose concentrations, 2) improved glucose tolerance, 3) increased fasting insulin, and increased insulin response to oral glucose, and 4) lowered ketone body, NEFA and glycerol concentrations and 3-hydroxybutyrate/acetoacetate ratios (these all became similar to the mean of the reference group). Most of these effects were reversed on withdrawal of the sulphonylureas, with values tending to return to those found after diet alone. The increased insulin response 

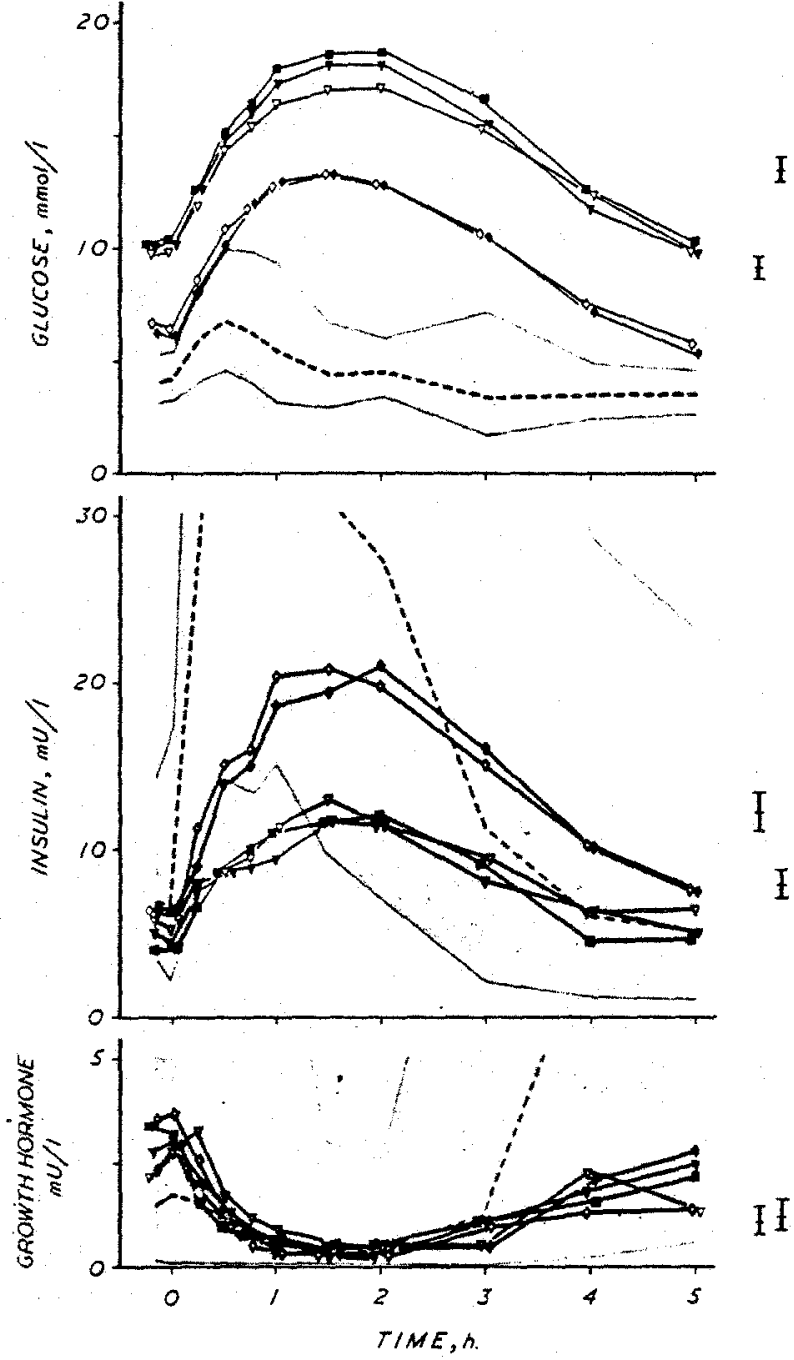

Fig. 5. Concentrations of glucose, insulin and growth hormone, showing pooled values after chlorpropamide, gibenclamide or a subsequent placebo: Symbols are for OGTT's: $\mathbf{n}$, after diet alone (OGTT 1); $\diamond$, after chlorpropamide; $\diamond$, after glibenclamide; $\nabla$, after placebo following chlorpropamide withdrawal; $\mathbf{\nabla}$, after placebo following glibenclamide withdrawal. Each line is the mean of 20 patients. The left-hand SEM (of the pairs at the right) refers to active treatment and the right-hand SEM to placebo. For further details, see the legend to Figure 2 and the text

in the face of lowered fasting blood glucose and smaller incremental rise in glucose probably reflects increased sensitivity of the B-cell to glucose. Although blood glucose concentrations remained abnormal on active treatment, ketone body, NEFA and glycerol concentrations, which had been relatively less abnormal than glucose after diet therapy, were returned to normal by sulphonylureas. Sulphonylurea treatment had little or no effect on hGH, lactate, pyruvate, lactate/pyruvate ratios or fasting lipids, all of which had been within their reference ranges after diet treatment.

The effects of sulphonylurea treatment on glucose tolerance and insulin secretion have been investigated by many workers. Whilst all have found improvements in glucose tolerance, the effects on insulin secretion have varied. Some authors have described, as we have, an increase in insulin concentrations after sulphonylureas [15-22] although some workers have noted an initial increase followed by a decrease in plasma insulin concentrations $[17,18$, $21,23]$. Other studies have found insulin to be unchanged [24-27], although transient early increases in insulin secretion were found in two of these studies [25, 27]. Some workers have described a diminished insulin response to oral glucose after sulphonylureas [28-30]. After withdrawing sulphonylureas, Barnes et al. [23] and Shenfield et al. [31], found no relapse in stimulated insulin secretion. Elkeles and Fraser [32] although finding a fall in insulin response on withdrawal of chlorpropamide, demonstrated no improvement in insulin response on restarting therapy, despite improvement in glucose tolerance.

In most of these studies, the effects of diet, weight loss and sulphonylurea treatment have not been adequately separated, particularly relevant where studies have included obese patients. In this study, we have not only separated effects due to diet alone, by a period of previous dietary treatment [33], but, in sequential active treatment and placebo periods, we have found successive improvements and relapses, respectively, in insulin secretion. Furthermore, these changes in insulin secretion were accompanied by appropriate reciprocal changes in glucose tolerance and concentrations of intermediary metabolites. We undertook the measurements of intermediary metabolites: 1) since it has been suggested that these may afford a better means of assessing diabetic control than measurements of glucose alone [34]; 2) to shed further light on the mode of action of the sulphonylureas. In our patients, these measurements gave no more information on diabetic control than did the measurements of glucose alone. Results of such measurements after sulphonylureas by other workers have been in agreement with those reported here: a fall in NEFA [35], no change in hGH [23-25], and no change in lactate or pyruvate [24]. Abramson and Arky [15] found sulphonylurea treatment to be accompanied by a fall in cholesterol, but their patients were obese and had been started on diet and a sulphonylurea simultaneously.

In some studies, withdrawal of sulphonylureas did not result in deterioration of glucose tolerance in all patients $[31,36]$, suggesting the possibility of a con- 
tinuing effect of the drug after its withdrawal. Since diet treatment alone, however, had not been shown to be ineffective in these studies, it is uncertain whether the findings are due to a continuing effect of sulphonylureas or to an alteration in diet. As a group, our patients showed no evidence of a lasting effect on glucose tolerance, although 3 patients showed virtually no deterioration in blood glucose concentrations on withdrawal of sulphonylureas (despite the initial failure of diet therapy alone). NEFA and glycerol concentrations showed slight evidence of a prolonged effect, in that they did not relapse as far after the second placebo as they did after the first.

The biochemical improvements brought about by the sulphonylureas were consistent with increased insulin secretion, both basally and in response to oral glucose. These changes accorded with the known actions of insulin as a hypoglycaemic and antilipolytic hormone. Since in vitro and acate in vivo studies in normal subjects have shown that tolbutamide stimulated insulin secretion, it was assumed that the hypoglycaemic effect of the drug in chronic diabetes was also mediated by increased insulin secretion. However some studies have shown improvement of glucose intolerance, without inereased insulin secretion $[23-27,31]$, suggesting extra-pancreatic effects of sulphonylurea. These drugs are known to affect, in vitro, tissues other than the pancreatic B-cell [37], although most of these effects have been observed at drug concentrations $(1-50 \mathrm{mmol} / \mathrm{l})[38,39]$, greatly in excess of those found in the plasma of sulphonylurea-treated diabetics $(0.2-0.7 \mathrm{mmol} / 1)[31,40,41]$. Direct effects on the pancreas can be demonstrated in vitro by a concentration of glibenclamide as low as $2 \mathrm{nmol} / 1$ [42]. In addition it is known that sulphonylureas are without effect in totally pancreatectomized animals [43], and in insulin-dependent diabetics [44], but it has been shown that sulphonylureas may increase insulin receptors in target tissues [45, 46]. From available evidence it seems likely that the main effect of sulphonylureas in non insulin dependent diabetes, is to increase the sensitivity of the B-cell response to changes in blood glucose concentrations. This hypothesis is supported by the relapse of both glucose tolerance and insulin secretion after withdrawal of the drugs. The absence of relapses in glycerol and NEFA concentrations after the second placebo period probably reflects the lack of relapse of basal insulin secretion then and the sensitivity of adipose tissue to insulin action [47].

There was no evidence that, in the doses used in this study, one drug was more effective than the other for treating diabetes. This contrasts with Clarke and Campbell's [48] report showing a lower overall primary failure rate of chlorpropamide than on gliben- clamide treatment, although theirs was a clinical observation, rather than a randomised cross-over study.

The relatively large doses used in our patients probably reflected the severity of their diabetes, as witnessed by the prevalence of complications. On the basis of the mean doses of each sulphonylurea at the end of active treatment periods, we found that on a weight basis glibenclamide was 26 times more potent than chlorpropamide (46 times more potent on a molar bases). This is comparable with Clarke and Campbell's [48] estimate of a 20 -fold difference in potency, favouring glibenclamide, but not with the 75-fold difference suggested by Bhatia et al. [49].

Acknowledgements. We are indebted to Sister S. L. Judd for performing the OGTT's and for other help, to Miss Cynthia Iles for dietetic supervision of the patients, to Ms Hilary Quine for measurements of insulin and growth hormone, to Ms Sandy Juul for measurements of NEFA and to Mr. Martin Bland for advice on the statistical analyses. Dr. R. R. McSwiney kindly allowed the use of routine Clinical Chemistry services for glucose and cholesterol measurements. We thank Hoechst Pharmaceuticals Ltd., the British Diabetic Association, St. Thomas' Hospital Special Trustees for grants in aid. Detailed statistical analysis of the hormone and metabolic concentrations are summarised in two additional tables, lodged in the Editorial Office of Diabetologia and available on request.

\section{References}

1. Loubatieres A (1944) Analyse du mecanisme de l'action hypoglycemiante du p-aminobenzenesulfamidoisopropylthiaxiazol (2254 RP). C R Soc Biol (Paris) 138: 766-767

2. Levine R, Pfeiffer EF (1969) HB 419, a new oral antidiabetic drug. Horm Metab Res 1 (Suppl 1): 1-92

3. Roth J, Prout TE, Goldfind ID, Wolfe SM, Muenzer J, Grauer LE, Marcus ML (1971) Sulfonylureas: Effects in vivo and in vitro. Ann Intern Med 75: 607-621

4. Trinder P (1969) Determination of blood glucose using an oxidase-peroxidase system with a noncarcinogenic chromogen. J Clin Pathol 22: 158-161

5. Trinder $P$ (1969) Determination of blood glucose using 4aminophenazone as oxygen acceptor. J Clin Pathol 22: 246

6. Sönksen PH (1976) Double-antibody technique for the simultaneous assay of insulin and growth hormone. In: Antoniades HN (ed) Hormones in human blood. Harvard University Press, Cambridge Mass London, p 176-199

7. Hohorst HJ, Kreutz, FH, Bücher Th (1959) Cber Metabolitgehalte und Metabolit-Konzentrationen in der Leber der Ratte. Biochemistry 332: 18-46

8. Williamson DH, Mellanby J, Krebs HA (1962) Enzymatic determination of $\mathrm{D}(-)$ - $\beta$-hydroxybutyric acid and acetoacetic acid in blood. Biochem J 82: $90-96$

9. Kreutz FH (1962) Enzymatische Glycerinbestimmung. Klin Wochenschr 40: 362-363

10. Carruthers M, Young DAB (1973) Free fatty acid estimation by a semi-automated fluroimetric method. Clin Chim Acta 49 : 341-348

11. Kessler G, Lederer H (1966) Fluorometric measurement of triglycerides. In: Automation in analytical chemistry. Technicon Symposia 1965. Medaid Inc, White Plains NY, p 341-344 
12. Levine J, Morgenstern S, Vlastelica D (1968) A direct Liebermann-Burchard method for serum cholesterol. In: Automation in analytical chemistry. Technicon Symposia 1967. Medaid Inc, White Plains NY, p 25-28

13. Perkins JR (1978) in Hormonal and metabolic responses to dietary and sulphonylurea treatments of chronic diabetes. $\mathrm{Ph}$. D. Thesis, University of London, $\mathrm{P} 47-51$

14. Winer BJ (1970) In: Statistical principles in experimental design. International Student (ed) McGraw Hill, London New York; Mladinska Kniiga, Ljubljana, p 140-224 and 578-618

15. Abramson E, Arky RA (1967) Treatment of the obese diabetic: A comparative study of placebo, sulfonylurea and phenformin. Metabolism 16: 204-212

16. Anderson J, Coulson R, Grassick BDM, Morris BA, Thomas WD, Tomlinson RWS, Woodroffe F (1970) Clinical and metabolic study in diabetic patients treated with glibenclamide. Br Med J II: 568-570

17. Chandalia HB, Hollobaugh SL, Pennington LF, Boshell BR (1969) Use of glibenclamide in maturity onset diabetes: effect of the drug on serum insulin levels. Horm Metab Res 1 (Suppl 1): 73-76

18. Chu P-C, Conway MJ, Krouse HA, Goodner CJ (1968) The pattern of response of plasma insulin and glucose to meals and fasting during chlorpropamide therapy. Ann Intern Med 68: $757-769$

19. Doar JWH, Thompson ME, Wilde CE, Sewell PFJ (1976) Diet and oral antidiabetic drugs and plasma sugar and insulin levels in patients with maturity-onset diabetes mellitus. $\mathrm{Br}$ Med J I: 498-500

20. Lauvaux JP, Mandart G, Heymans G, Ooms HA (1972) Effect of long-term tolbutamide treatment on giucose tolerance and insulin secretion in maturity-onset diabetes without obesity. Horm Metab Res 4: 58-62

21. Sheldon J, Taylor KW, Anderson J (1966) The effects of longterm acetohexamide treatment on pancreatic islet cell function in maturity-onset diabetes. Metabolism 15: 874-883

22. Tsalikian E, Dunphy TW, Bohannon NV, Lorenzi M, Gerich JE, Forsham PH, Kane JP, Karam JH (1977) The effect of chronic oral antidiabetic therapy on insulin and glucagon responses to a meal. Diabetes 26: 314-321

23. Barnes AJ, Garbien KJT, Crowley MF, Bloom A (1974) Effect of short and long term chlorpropamide treatment on insulin release and blood glucose. Lancet II: $69-72$

24. Davidson M, Lewis AAG, de Mowbray RR, Boucher BJ, Oakley NW, Nabarro JDN, Ginsberg J, Beaconsfield P (1970) Metabolic and clinical effects of glibenclamide. Lancet I: $57-61$

25. Feldman JM, Lebovitz HE (1971) Endocrine and metabolic effects of glibenclamide. Diabetes 20: 745-755

26. Hadden DR, Bhatia SK, Rigas A, Weaver JA, Montgomery DAD (1969) Circadian variation of glucose, insulin and free fatty acids during the long-term use of oral hypoglycemic agents in diabetes mellitus with special reference to HB419. Horm Metab Res 1 (Suppl 1): 77-80

27. Hecht A, Gershberg H, Hulse M (1973) Effect of chlorpropamide on insulin secretion in diabetics: its relationship to the hypoglycemic effect. Metabolism 22: 723-733

28. Boshell BR, Fox OJ, Roddam RF, Hill PS (1967) The effect of sulphonylurea agents on insulin secretion and insulin reserve. In: Butterfield WJH, Van Westering W (ed) Tolbutamide after ten years. International Congress Series No 149. Excerpta Medica Foundation Amsterdam New York London Milan Tokyo Buenos Aires, p 286-297

29. Fox OJ, McAdams GL, Boshell BR (1967) Effect of sulfonylureas on insulin secretion and insulin reserve. Clin Res 15: 43

30. Reaven GM, Dray J (1967) Effect on chlorpropamide on serum glucose and immunoreactive insulin concentrations in patients with maturity-onset diabetes mellitus. Diabetes 16 : $487-492$

31. Shenfield GM, Logan A, Shirling D, Baird J (1977) Plasma insulin and glucose levels in maturity onset diabetics treated with chlorpropamide. Diabetologia 13: 367-371

32. Elkeles R, Fraser TR (1970) The effect of short and long term chlorpropamide therapy on glucose tolerance. Diabetologia 6 : 148

33. Perkins JR, West TET, Sönksen PH, Lowy C, Iles C (1977) The effects of energy and carbohydrate restriction in patients with chronic diabetes mellitus. Diabetologia 13: 607-614

34. Alberti KGMM, Hockaday TDR (1975) The biochemistry of the complications of diabetes. In: Keen $\mathrm{H}$, Jarrett $\mathrm{J}$ (ed) Complications of diabetes. Edward Arnold, London, p 221-264

35. Stone DB, Brown JD (1966) Effect of sulfonylurea drugs on plasma free fatty acid and blood glucose concentrations in man. Diabetes 15: 314-318

36. Tomkins AM, Bloom A (1972) Assessment of the need for continued oral therapy in diabetics. Br Med J I: 649-651

37. Feldman JM, Lebovitz HE (1969) Appraisal of the extrapancreatic actions of sulfonylureas. Arch Intern Med 123: 314-322

38. Williams RH, Tucker BW (1956) Hypoglycemic actions of tolbutamide and carbutamide. Metabolism 5: 801-806

39. Mirsky IA, Perisutti G, Diengott D (1956) The inhibition of insulinase by hypoglycemic sulfonamides. Metabolism 5: 156-161

40. Bair JD, Duncan LJP (1957) An analysis of the hypoglycaemic response to tolbutamide. Scott Med J 2: $341-350$

41. Stowers JM, Mahler RF, Hunter RB (1958) Pharmacology and mode of action of the sulphonylureas in man. Lancet $I$ : 278-283

42. Mariani.M-M (1969) The action of sulfonylureas on the insulin secretion of the perfused rat pancreas. Acta Diabetol Lat 6 (Suppl 1): 256-270

43. Loubatieres A (1957) The hypoglycemic sulfonamides: history and development of the problem from 1942 to 1955 . Ann NY Acad Sci 71: 4-11

44. Pfeiffer EF, Pfeiffer M, Ditschuneit H, Ahn C-S (1959) Clinical and experimental studies of insulin secretion following tolbutamide and metahexamide administration. Ann NY Acad Sci 82: $479-495$

45. Feinglos MN, Lebovitz HE (1978) Sulphonylureas increase the number of insulin receptors. Nature 276: 184-185

46. Greenstein BD (1979) Improved insulin receptor assay: effects of an antidiabetic sulphonylurea on liver membrane insulin receptors from obese hyperglycaemic mice. $\mathrm{Br}$ J Pharmacol 66: $317-322$

47. Rabinowitz $\mathrm{D}$, Zierler $\mathrm{KL}$ (1965) The action of insulin in man in the postabsorptive and postprandial states. Postgrad Med J 41: $67-72$

48. Clarke BF, Campbell IW (1975) Long-term comparative trial of glibenclamide and chlorpropamide in diet-failed, maturityonset diabetics, Lancet I: 246-248

49. Bhatia SK, Hadden DR, Montgomery DAD, Weaver JA (1970) Glibenclamide therapy in diabetes mellitus. Br Med J II: $570-572$

Received: February 1, 1979,

and in revised form: August 1, 1980

Prof. P. H. Sönksen

St. Thomas' Hospital

London SEl $7 \mathrm{EH}$

England 